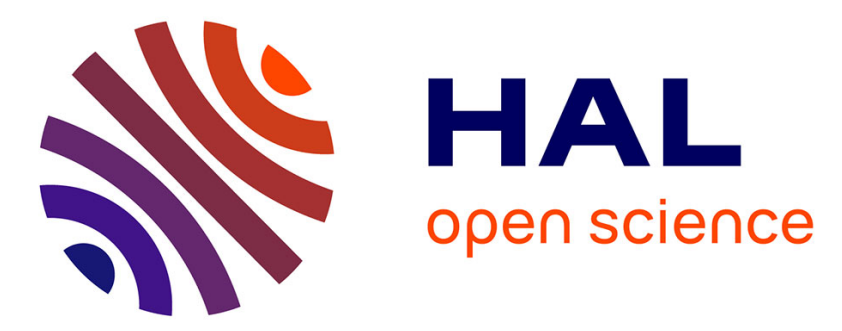

\title{
How resilient is La Réunion in terms of international tourism attractiveness: an assessment from unit root tests with structural breaks from 1981-2015
}

Amélie Charles, Olivier Darné, Jean-François Hoarau

\section{- To cite this version:}

Amélie Charles, Olivier Darné, Jean-François Hoarau. How resilient is La Réunion in terms of international tourism attractiveness: an assessment from unit root tests with structural breaks from 1981-2015. Applied Economics, 2019, 51 (24), pp.2639-2653. 10.1080/00036846.2018.1558349 . hal02053296

HAL Id: hal-02053296

https://hal-audencia.archives-ouvertes.fr/hal-02053296

Submitted on 1 Mar 2019

HAL is a multi-disciplinary open access archive for the deposit and dissemination of scientific research documents, whether they are published or not. The documents may come from teaching and research institutions in France or abroad, or from public or private research centers.
L'archive ouverte pluridisciplinaire HAL, est destinée au dépôt et à la diffusion de documents scientifiques de niveau recherche, publiés ou non, émanant des établissements d'enseignement et de recherche français ou étrangers, des laboratoires publics ou privés. 


\title{
How resilient is La Réunion in terms of international tourism attractiveness: an assessment from unit root tests with structural breaks from 1981-2015
}

\author{
Amélie CHARLES (Audencia Business School), \\ Olivier DARNÉ (LEMNA, University of Nantes) ${ }^{\dagger}$ \\ Jean-François HOARAU (CEMOI, University of La Réunion) $)^{\ddagger}$
}

\begin{abstract}
Even if local policymakers increasingly claim that tourism is one of the key factors of future economic development for the French small island La Réunion, international tourist arrivals are observed to be locked in a stagnation phase since the beginning of the 2000s. Starting from this stylised fact, this article aims to study if this phenomenon results from major external events hurting this economy regularly. Next, by using univariate unit root procedures with structural breaks, we test for evidence of permanent or transitory effects of external shocks on international tourist inflows (total, by source markets, and by category) over the period 1981-2015. Finally, the empirical analysis allow us to reject the null of a unit root. Then, stagnation of tourism arrivals to La Réunion is not due to exogenous shocks but probably results from endogenous impediments within the domestic tourism industry and unsuitable public policies.
\end{abstract}

Keywords: External shocks, La Réunion, life cycle model, tourism, unit root. JEL Classification: C22; L83

${ }^{*}$ Audencia Nantes, School of Management, 8 route de la Jonelière, 44312 Nantes, France. Email: acharles@audencia.com.

${ }^{\dagger}$ LEMNA, University of Nantes, Chemin de la Censive du Tertre, BP 52231, 44322 Nantes, France. Email: olivier.darne@univ-nantes.fr.

¥CEMOI, University of La Réunion, 15 avenue René Cassin CS 9200397744 Saint-Denis Cedex, France. Email: jfhoarau@univ-reunion.fr. 


\section{Introduction}

Undoubtedly, tourism is one of the most dynamic exporting sectors in the world economy. For some countries, this activity contributes more to domestic economic growth than traditional exports' sources like agriculture or manufacturing industry. The role of tourism is even more relevant in the context of small island economies (SIE). For most SIEs, it is a notable and perhaps the only alternative to the industrial sector (Logossah and Maupertuis, 2007; Bertram and Poirine, 2007). Notably, despite positive economic spillovers, tourism is prone to vulnerability and weakens sustainable development for small entities in the long term.

Four main problems with relying on tourism must be exposed. First, several leakages can offset the increase in domestic income due to tourist expenditures (Nowak and Sahli, 2010). Second, a strong competition may occur between sectors in terms of land, labour, and capital, which generates a 'Dutch disease' dynamic resulting in the fall of earlier exporting sectors (Nowak and Sahli, 2007). Third, tourism specialisation can be the cause of its own destruction. Beyond a specific threshold (the so-called tourist carrying capacity), the number and behaviour of tourists damage the attractiveness of the destination based on ecological and cultural balance that leads to a decline (Butler, 2011). Fourth, tourism is prone to instability (UNEP and WTO, 2006) because of conjunctural fluctuations in the foreign source markets and international events like financial and economic crises or unexpected large external shocks (e.g. health crises, natural disasters, wars, terrorism).

The case of La Réunion is a good example (Perrain and Jean-Pierre, 2016). The importance of the tourism sector for the local economy is significant: by 2012, foreign tourists' expenditures were $€ 315$ million, making tourism the primary export, followed by goods ( $€ 307$ million). Despite of hopeful growth in the 1980s and 1990s (an annual average rate of approximately $8 \%$ ), since the beginning of the 2000s international arrivals to the French overseas territory are observed to be locked in a stage of stagnation with an average of approximately 425,000 tourists per year. Evolution of the share of foreign tourism expenditures in the GDP confirms this global trend: we observe a growth phase that increases to a maximum in 2000 of $3.2 \%$ of GDP, followed by a decrease to $2.2 \%$ in 2012 . Moreover, the destination is very exposed to large unanticipated exogenous shocks. Alongside potential natural disasters due to cyclone phenomena that regularly damage the island, several major external and internal events, namely, the context of terrorism following the September 11 terrorist attacks, health crisis of 'Chigungunya' in 2005-2006, international financial crisis in 
2008, and shark crisis since 2012, could have hurt the local economy dramatically. Considering this high degree of exposure to natural risks, observers question the vulnerability of this destination that is the real possibility of a sustainable development process based on tourism for the French small island.

Some studies have shown that tourist arrivals are affected by major external or internal events due to financial crises, terrorist attacks, changes in political regimes or natural disasters, such as the 1999 earthquake in Taiwan (Huang and Min, 2002), 1987 political coup in Fiji (Narayan, 2005), Bali bombing (Smyth et al., 2009), Asian crisis (Narayan and Prasad, 2008), and the September 11 attack (Saleh et al., 2011). The topic of whether these large shocks have permanent or transitory effects on tourist arrivals has important policy implications in the context of the sustainability of the tourism industry. If large shocks on tourist arrivals are permanent, empirical support is provided for questioning the sustainability of the tourist sector due to the vulnerability of the tourism to shocks, suggesting the government should initiate reforms to increase the diversity and sustainability of the economy; however, if the external shocks are short-lived (transitory), the long-run returns from investment in the tourist industry are sustainable. All the examples in literature have found that the large shocks have transitory effects.

The aim of this paper is to examine whether tourist arrivals (total arrivals, by source markets, and by category) in La Réunion are affected by permanent or transitory shocks due to major external or internal events over the period 1981-2015. We consider that these major events represent large shocks that occur infrequently (lowfrequency shocks), but the time of their arrival is random. Our approach results from the numerous examples of random, heterogeneous, and infrequent events that could have a dramatic impact on tourist-arrival time series. This type of event includes, for example, the September 11 terrorist attacks, health crisis of 'Chigungunya' in 2005-2006, international financial crisis in 2008, and shark crisis since 2012. For this reason, we search for the presence of these infrequent large shocks (permanent and/or temporary) in the form of outliers in the number of tourist arrivals to La Réunion. The points are identified and corrected by using intervention analysis, originally proposed by Box and Tiao (1975) and improved by Chen and Liu (1993) and Gómez and Maravall (1997). We also detect structural breaks in the slope of the trend, which we observed to be the case for La Réunion from the early 2000s, by using the test developed by Perron and Yabu (2009), whose breaks would be rather endogenous. This type of approach should provide information concerning the nature and magnitude of the shocks on the number of tourist arrivals. 
We also examine whether tourist arrivals in La Réunion are best characterised by a unit root process (random walk) or stationary process. If tourist arrivals are characterised by a unit root process, the implication is that effects of shocks, assumed to be randomly generated for every observation period (frequent small shocks), will have a permanent effect and tourist arrivals will not return to their stable long-term growth path. Otherwise, these permanent shocks due to innovations in tourism infrastructure are the main source of tourist-arrival growth trends. Notably, if international tourist arrivals are characterised as a stationary process, the implication is that following a (frequent small) shock, tourist arrivals return to their long-run trend path and the impact of the shock on varied tourist numbers will be only transitory. Therefore, movements in tourist arrivals are associated with temporary fluctuations so that a (frequent small) shock such as innovation should have no impact on long-run tourist numbers. The random walk hypothesis for visitor arrivals in La Réunion is examined in this study by applying appropriate unit root tests according to the breaks detected in the previous step. Conducting univariate unit root tests is crucial, because source markets may respond differently to a shock. According to our review of the literature, this study is the first to analyse the effect of large shocks and stationary properties of tourist arrivals in La Réunion 11

The remainder of the paper is organised as follows. Section 2 highlights major stylised facts for La Réunion in the field of tourism development. Section 3 presents the theoretical framework by asserting the usual suspects that explain the potential vulnerability of the small French island's tourism arrivals. Section 4 exposes the empirical methodology. Section 5 displays and analyses the empirical findings. Section 6 concludes.

\section{Main stylised facts}

By 2012, global tourism (foreign visitors and locals) in La Réunion was $8 \%$ of GDP, that is, $€ 846$ million. If we focus on the foreign side, tourism represents approximately $2.2 \%$ of GDP, corresponding to a receipt of $€ 315$ million (Perrain and Jean-Pierre, 2016) and 3.2\% of total employment. Tourism is the primary export of La Réunion and far ahead of exports of goods; however, a contrasting conclusion emerges from

\footnotetext{
${ }^{1}$ Notably, few studies have examined the effect of large shocks and stationary properties of tourist arrivals (e.g., Huang and Min, 2002; Bhattacharya and Narayan, 2005; Narayan, 2005; Narayan and Prasad, 2008; Lean and Smyth, 2009; Saleh et al., 2011) but with different methodology approaches. See subsection 5.2 for a discussion on these studies.
} 
international comparisons with the other SIE.

This French overseas territory is one of the least dependent islands regarding tourism earnings with Suriname and Haiti (Perrain and Jean-Pierre, 2016). This finding is observed to be more obvious when considering its insular neighbours (Table 1). Contrary to La Réunion contribution of tourism to wealth creation is significant in Maldives (14.0\%), Seychelles (6.4\%), and Mauritius (3.8\%). The same conclusion holds for the other French overseas regions (Polynesia, Martinique, Guadeloupe and Guyana). The economic impact per capita for La Réunion (US\$516) is also far behind that for the other islands, except for Comoros. This relative weak economic contribution of the tourism sector can be analysed on the quantitative and structural sides.

Table 1: Foreign tourism earnings for a several small island economies

\begin{tabular}{|l|c|c|}
\hline Pays & in \% of GDP (2012) & dollar per capita (2013) \\
Maldives & 14.0 & 4741 \\
Polynesia & 6.9 & 1455 \\
Seychelles & 6.4 & 2593 \\
Mauritius & 3.8 & 1118 \\
Martinique & 3.6 & 1252 \\
Guadeloupe & 3.2 & 1433 \\
Comoros & 3.2 & 41 \\
Guyana & 2.4 &.. \\
La Réunion & 2.2 & 516 \\
\hline
\end{tabular}

Sources: Blancard and Hoarau (2016), Perrain and Jean-Pierre (2016).

A first relevant explanation emerges from the evolution of tourist arrivals over the period 1989-2015 (Graph11). Two main regimes are present. From 1989 to the beginning of the 2000s, a phase of dynamic growth was observed with tourist inflows to La Réunion increasing from 181,769 to 429,999 , that is, by a multiplicative factor of $137 \%$. This boom resulted from two joined factors: a strong demand from the French market in search for new 'sun' destinations and a local supply, in terms of hotel infrastructures and air transport conditions that grew in accordance with this dynamic demand (Rochoux, 2016). Since 2000, the destination has been in a phase of stagnation, with total tourist numbers, in average, of 425,000 per year.

In this study, two arguments can be asserted to explain these data. First, many large exogenous events had deep negative effects on La Réunion over the recent period: 
(i) the international tourism turmoil in 2001-2002 following the terrorist attacks of September 11, (ii) health crisis of 'Chigungunya' in 2006, (iii) international financial crisis in 2008-2009, and (iv) the shark attacks that began in 2012. Second, some observers highlight that the absence of a common vision from the stakeholders creates a further slowdown of development of the destination. In particular, the absence of a consensus prevented the establishment of the necessary environmental conditions to create a clear identity for the destination and 'attract vibrant entrepreneurs who have the vision, the drive, and the cash to revolutionise the market' (Russell and Faulkner, 2004, p.564).

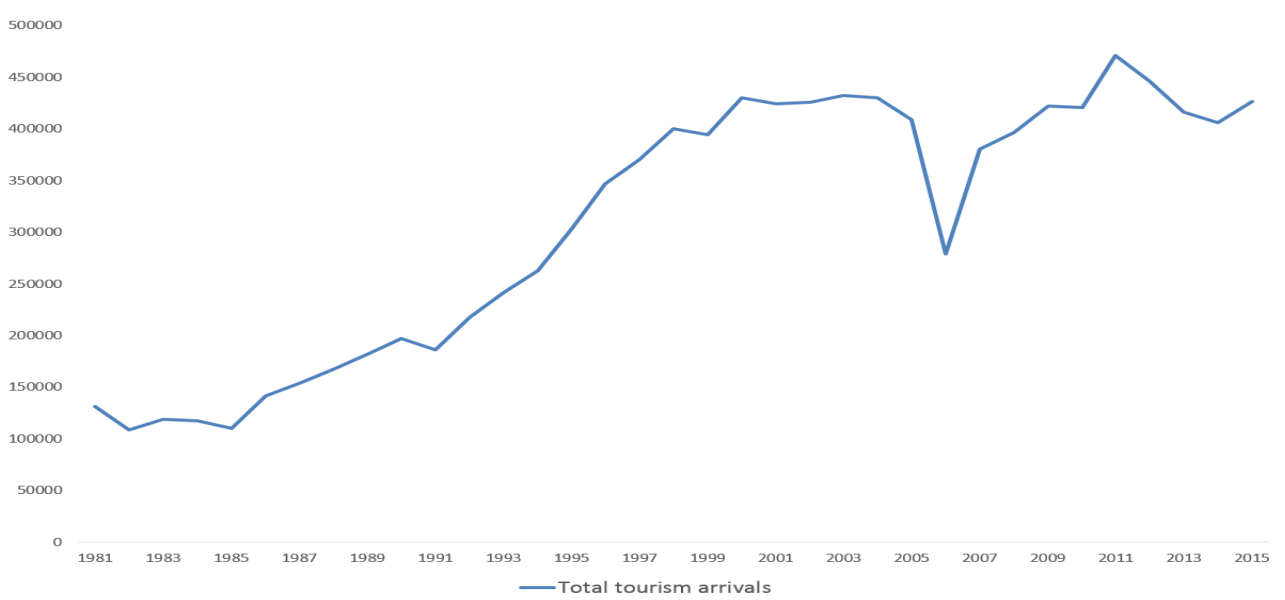

Figure 1: Total tourist arrivals to La Réunion (numbers per year)

The vulnerability of La Réunion's tourism sector is even more relevant when we focus on the structural dimension. Disaggregating the total arrival flows by source markets, we observe a high and dangerous historical dependence from the mainland (Figure 2). Notably, $75 \%$ of total inflows are from continental France, $8 \%$ from the European Union (especially Belgium and Germany), and 17\% from others (mainly Mauritius, Madagascar, and Mayotte). Recently, local policymakers have unsuccessfully attempted to diversify the source markets by developing promotion campaigns directed at Chinese and Indian travellers. 


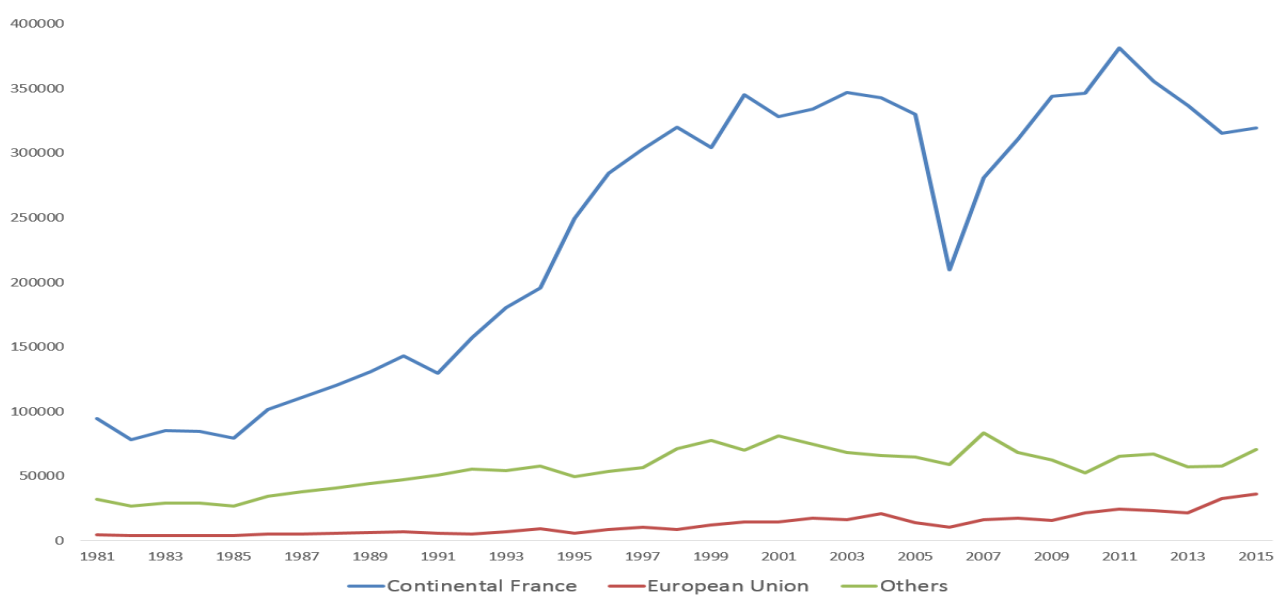

Figure 2: Tourist arrivals to La Réunion by source markets (numbers per year)

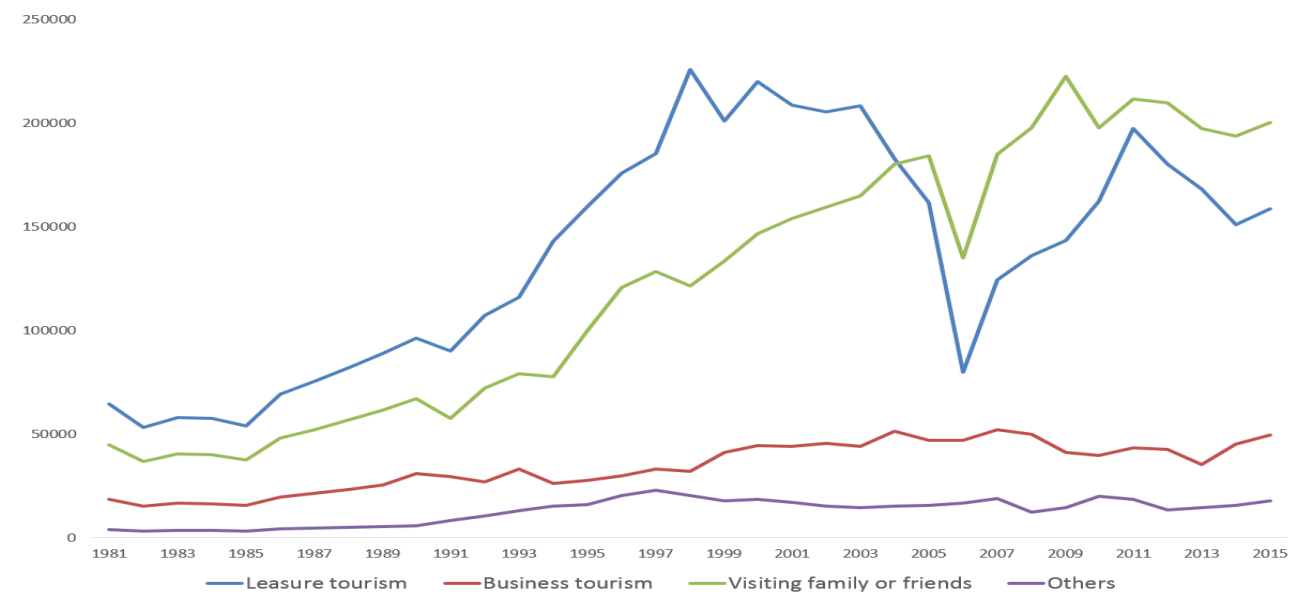

Figure 3: Tourist arrivals to La Réunion by motivations (numbers per year)

Now, if we disentangle the total inflows between family or friends' visitors, business tourism and leisure tourism, this difficult situation becomes more evident (Figure 3): business tourism is obviously marginal. Otherwise, the evolution of leisure tourism, the more profitable form of foreign tourism in terms of financial earnings, shows several main periods: (i) strong growth from 1981 until 1998; (ii) a phase of stagnation from 1998-2004; (iii) a marked decrease magnified by the 'Chigungunya' crisis from 2003-2007; (iv) a sensible recovery from 2007 until 2011; and (v) another phase of decline since 2011. In summary, the number of tourist arrivals for leisure has been divided by two over the period 1998-2015. Since 2004 family or friends' visitors are become the major category of tourism inflow in La Réunion, exceeding the categories of leisure and business tourism. 


\section{The theoretical framework}

Theoretical roots of the tourism vulnerability of La Réunion can be found in the 'tourism optimum' literature. The concept of tourism optimum is the alternative vision of the so-called 'tourism-led-growth' hypothesis (Balaguer and CantavellaJorda, 2002). Nobody contests the positive role of tourism in the short term, but no such evidence exists concerning the sustainability of economic growth in the long term due to the presence of negative economic, social, and ecological spillover effects (Logossah and Maupertuis, 2007) $2^{2}$ In other words, a maximum level exists, namely, an optimal level, from which negative effects of tourism specialisation dominate positive effects and overrule the sustainability of the tourist activity (Lozato-Giotart, 2003; Lozato-Giotart and Balfet, 2004).

\subsection{The Standard approach: the Tourism Area Life Cycle model}

Despite several conceptual and empirical limits (Choy, 1992; Bianchi, 1994; Prideaux, 2000; Aguilo et al., 2005; McKercher, 2006), the tourism area life cycle (TALC) model remains the more influential theoretical approach in the field (Butler, 1980, 2011) $3^{3}$ In short, the TALC model states that all tourism destinations are characterised by a common dynamic process reproducing a S-shaped curve and experiencing a series of stages from exploration to involvement, development, consolidation, stagnation, and post-stagnation (see Graph 4).

Exploration and involvement are the first steps of a nascent industry where the numbers and frequency of visits remain weak. Tourists use largely domestic facilities and contact with locals. Public investments, notably, in tourism infrastructures, are low. The stages of development and consolidation constitute the golden states of the tourism destination. A take-off process is clearly occurring even if several signs of a slowdown in growth are observed at the end of the stage of consolidation. The footprint

\footnotetext{
${ }^{2}$ Adaou and Clerides (2010) and Holzner (2011) indicate that tourism exerts a marginal time decreasing positive impact on economic growth. Jin (2011) states that tourism has a positive impact in the short term but a negative impact in the long term. Geronimi et al. (2016) asserts a nonlinear relationship between tourism and growth; thus, beyond a threshold of tourism specialization, vulnerability increases and impedes economic growth.

${ }^{3}$ Since its foundation, many conceptual improvements have been realized: (i) additional steps in the general path (Agarwal, 1994, 2002, 2006), (ii) the presence of heterogeneity of the tourism product and possible superposition of multiple cycles (Zimmerman, 1997; Baum, 2006), and (iii) introduction of micro-foundations within the standard framework (Coles, 2007, 2009). Moreover, many applied works have provided strong support to its availability to the current context (Moss et al., 2003; Dodds and McElroy, 2008; Cole, 2009; Komppula et al., 2010).
} 
of tourism activity is now apparent based on the number of tourists per year, which can equal and even exceed the number of permanent residents. Then, the destination enters stagnation, that is, the tourism optimum stage that represents the maximum number of visits per year the resort experiences in its life cycle. The final stage is post-stagnation. Notably, the destination's performance (rejuvenation or decline) depends on the ability of the policymakers in charge of the territorial policy to manage or restore, if necessary, the economic, social, and ecological carrying capacity ${ }^{4}$

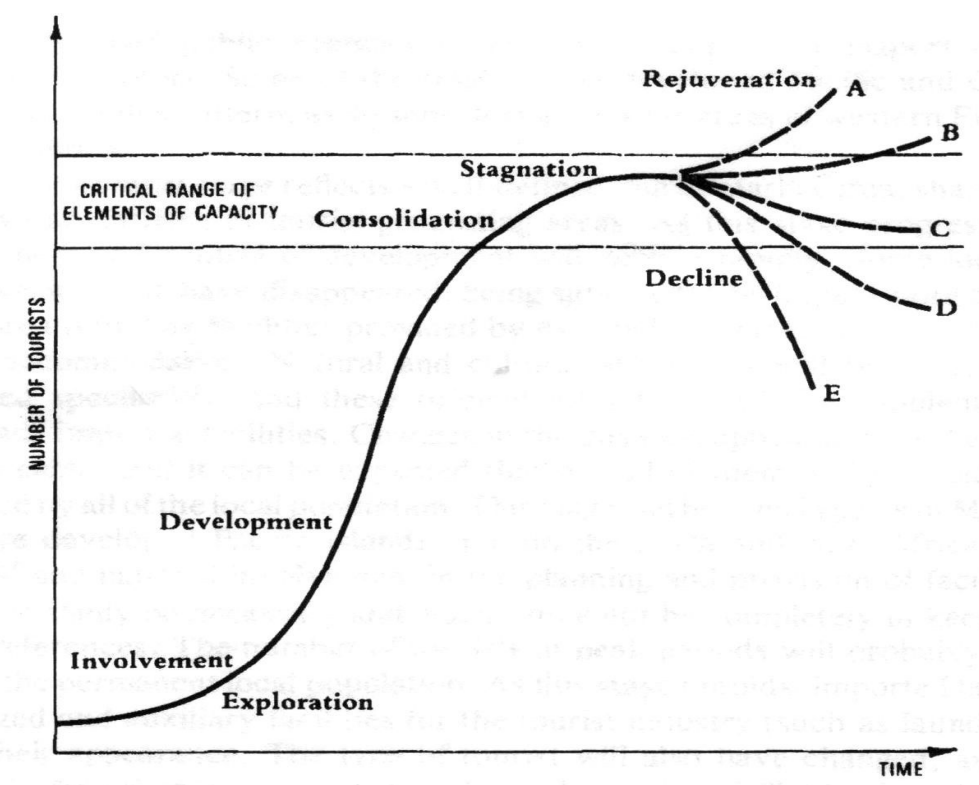

Figure 4: The TALC model

Considering the time shape of the total tourist arrivals series (Figure 1), the TALC model indicates that La Réunion has been in the stagnation phase since 2000. Such a conclusion would be mistaken, because this phase characterises mature and mass tourism destinations that do not correspond to the situation of the small French island. More precisely, running a clustering analysis based on the components of the Tourism Penetration Index developed by McElroy and de Albuquerque (1998) 5 over a sample of 47 SIE for the year 2013, Blancard and Hoarau (2016) asserted that La Réunion belongs to the cluster of the least penetrated tourism entities, that is, the cluster

\footnotetext{
${ }^{4}$ See Butler (2011) for a complete discussion about these different stages.

${ }^{5}$ This composite indicator is created from three variables: the visitor spending per resident population, average daily visitors density per 1,000 population, and number of hotel rooms per square kilometer.
} 
corresponding to the exploration stage. Then, the standard TALC model is not very informative concerning the dynamics conditioning the evolution of this destination.

\subsection{Adding Chaos principles}

The quasi linearity of the evolution curve stated by the TALC approach is theoretically funded but actually corresponds to the very long term. By contrast, observation shows that actual tourist destinations are confronted by strong instability, generating gaps from the trend given by the TALC curve in the short and medium term 6

Russel and Faulkner (2004), Russel (2006), and Cole (2009) argue that providing a better appreciation for the paradoxical nature of a destination by combining the principles of chaos and complexity with the TALC model is possible. Specifically, the transition from one stage to the next is not linear or deterministic insofar as the tourism destination, whatever its maturity, highly depends on a set of unpredictable triggers. Moreover, the perturbations resulting from impacts of these unpredictable triggers are also unpredictable with a magnitude out of proportion to the initial shock.

Notably, each phase of the life cycle may enter into a period of instability, driven by fundamental shifts in relationships between the stakeholders of destination and the tourists. In each phase of its development, specific manifestations of chaos are present ('butterfly' effect, lock-in effect, bifurcation, 'edge of chaos'), implying that the tourism destination is a process continuously evolving and adapting. According to the specific combinations of the triggering factors, chaos effects can either facilitate or impede growth, progressing the cycle or causing stagnation and decline.

Consequently, it is more appropriate to represent the new approach by combining the TALC model with chaos principles as cyclic (Graph5). Obviously, this theoretical framework is more informative concerning the case of La Réunion. By considering these new conceptual insights and empirical results from Blancard and Hoarau (2016) together, the French destination is observed to be persistently locked in the stage of exploration.

According to our review of the literature, two types of triggers have been identified according to their exogenous or endogenous nature (Faulkner and Russel, 2001). First,

\footnotetext{
${ }^{6}$ Butler (2009) admits that the TALC model conforms to old destinations but is unsuitable for the new products characterized by differentiation and rapid innovative changes in a context of high international competition, strong mobility of potential visitors, and unprecedented reduction in the distance (i.e. transport times and costs). In particular, the model does not accommodate the unpredictable factors that trigger development or decay.
} 


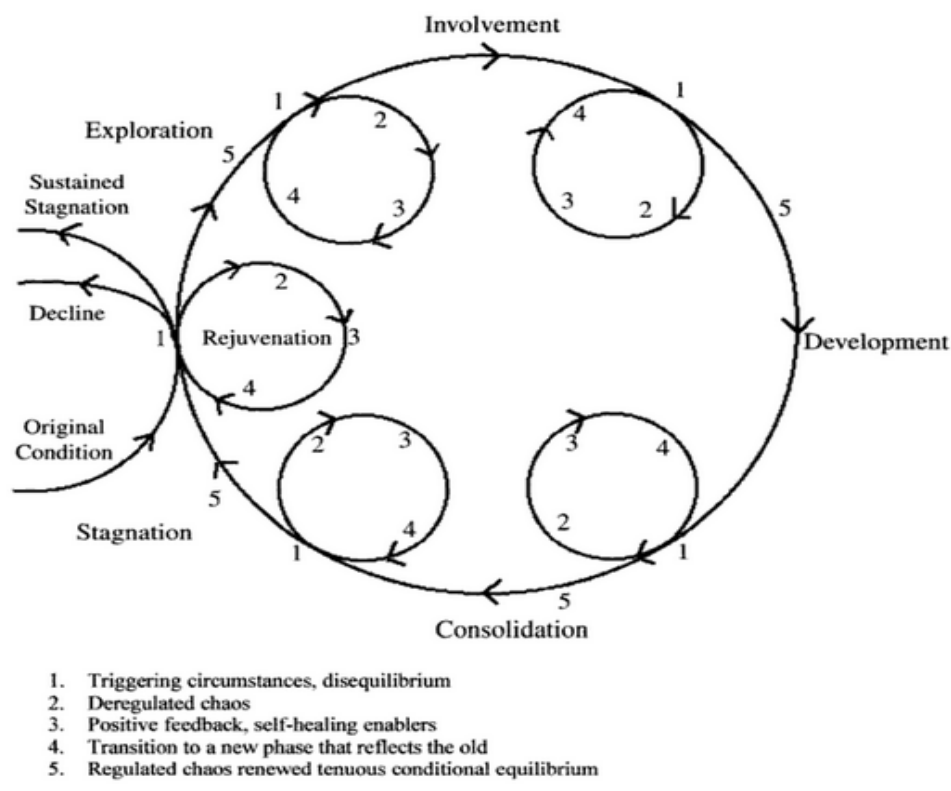

Figure 5: The TALC approach with chaos

are major extreme events which constitute exogenous shocks, such as health crises, international economic and financial crises, terrorism, wars, and natural disasters; of these one-off shocks, these latter damage the attractiveness of the destination sharply and instantly (and in some cases increase the attractiveness of competitors) with the possibility of a persistent impact in accordance with the butterfly effect principle. Second, the entrepreneurial skills of the territory and the presence of an economic, social, and political environment prone to entrepreneurship development are fundamentals.

The transition of a stage to the next strongly depends on the role of entrepreneurs and their relationships with local community and governance bodies. Of course, the ability to identify the type of triggers involved is crucial to design the adapted economic policies. If the resort is often hurt by disturbing and permanent external shocks, relying on tourism would be too dangerous. In this case, policymakers must opt for a strategy of diversification rather than tourism specialisation. If the problem is instead endogenous, due to the absence of underlying conditions for increasing entrepreneurial activities, policymakers must determine and implement a new tourism policy suited to the current stage of the economy's life cycle. Notably, the type of entrepreneurs and environment they require to develop are stage-dependent (Russel and Faulkner, 2004). 


\section{Methodology}

To assess the vulnerability of La Réunion relative to shock exposure, we implement an econometric strategy based on three stages. The first two steps aim to detect the presence of exogenous and endogenous breaks in the series of foreign tourism inflows. In a third step, we use a set of unit root tests adapted to the nature of identified breaks to draw conclusions regarding the temporary or persistent effect of shocks. All the tests are presented in detail in the Appendix.

\subsection{Detecting breaks}

\subsubsection{Detection of exogenous breaks}

Breaks in macroeconomic series reflect extraordinary, infrequently occurring events or shocks that have major effects on modeling macroeconomic time series. There are several methods stemming from the statistical field for detecting breaks or outliers based on the so-called intervention analysis approach, as originally put forward by Box and Tiao (1975). In this paper, we implement an improved detection algorithm proposed by Chen and Liu (1993), which is readily available with slight modifications by Gómez and Maravall (1997). Especially, we focus on break detection from AutoRegessive Integrated Moving-Average (ARIMA) models to emphasize the large shocks that have affected the series.

Let's assume that we observe $\left(y_{t}\right)$ the annual series which follows the following process:

$$
y_{t}=z_{t}+f(t)
$$

where

$$
z_{t}=\frac{\theta(L)}{\alpha(L) \phi(L)} a_{t} \quad a_{t} \sim N\left(0, \sigma_{a}^{2}\right)
$$

where $z_{t}$ is an $\operatorname{ARIMA}(p, d, q)$ process $\unlhd^{7}$ ( $L$ being the usual lag operator), and $f(t)$ contains exogenous disturbances or breaks. Following Chen and Liu (1993), we will consider three various types of breaks: additive outlier (AO), level shift (LS) and

\footnotetext{
${ }^{7}$ The orders $p$ and $q$ of the ARIMA model are based on specification tests and information criteria.
} 
temporary change (TC). The specifications for different $f(t)$ are as follows:

$$
\begin{array}{ll}
\text { AO: } & f_{A O}(t)=\omega_{A O} I_{t}\left(\tau_{j}\right) \\
\text { LS: } & f_{L S}(t)=[1 /(1-L)] \omega_{L S} I_{t}\left(\tau_{j}\right) \\
\text { TC: } & f_{T C}(t)=[1 /(1-\delta L)] \omega_{T C} I_{t}\left(\tau_{j}\right)
\end{array}
$$

where $\omega_{i}$, for $i=\mathrm{AO}, \mathrm{LS}, \mathrm{TC}$, denotes the magnitude of the break ${ }^{8}, I_{t}\left(\tau_{j}\right)$ is an indicator function that takes the value of 1 at time $t=\tau_{j}$ and 0 otherwise; $\tau_{j}$ being the unknown date at which the break occurs, with $j=1, \ldots, m$, and $m$ is the number of breaks. These various types of breaks differently affect the observations: AO causes an immediate and one-shot effect on the observed series; LS produces an abrupt and permanent step change in the series (permanent shock); TC produces an initial effect which dies out gradually with time (transitory shock). In this latter case, the parameter $\delta$ controls the pace of the dynamic dampening effect $(0<\delta<1)$. Note also that the detection algorithm provides an estimated date for the break through a sequential procedure.

\subsubsection{Detection of endogenous breaks}

We now study the presence of endogenous breaks, i.e. breaks in the level and/or the slope of the trend function.

The test is based on the following general model:

$$
\begin{gathered}
y_{t}=\mu_{0}+\beta_{0} t+\sum_{j=1}^{K} \beta_{j} D T_{j t}+u_{t}, \quad t=1, \ldots, T, \\
u_{t}=\alpha u_{t-1}+v_{t}, \quad t=2, \ldots, T, \quad u_{1}=v_{1},
\end{gathered}
$$

where $D T_{j t}=\left(t-T_{j}\right) \mathbb{I}\left(t>T_{j}\right), j=1, \ldots, K$. A break in the trend occurs at time $T_{j}=\left[T \lambda_{j}\right]$ when $\beta_{j} \neq 0$. The dates of breaks $\left(T_{j}\right)$ and the number of breaks $(K)$ are treated as unknown. The error $u_{t}$ is allowed to be either $I(0)(|\alpha|<1)$ or $I(1)(\alpha=1)$. The stochastic process $\left\{v_{t}\right\}$ is assumed to be stationary but not necessarily i.i.d. thereby permitting a general error structure for $u_{t}$.

Firstly, we test for the presence of one structural break in the slope $(K=1)$ which is formulated by the null hypothesis that $\beta_{1}=0$ versus an alternative hypothesis $\beta_{1} \neq 0$ (ExpW test). Perron and Yabu (2009b) propose a hypothesis testing approach on the

\footnotetext{
${ }^{8}$ More precisely, it is considered that AOs are outliers which are related to an exogenous change in the series with no permanent effects, whereas TCs and LSs are more in the nature of structural changes. TCs represent short-lived shifts in a series with a return to previous levels whereas LSs are more the reflection of permanent shocks. In the remainder of the paper, we use the term "break" for AO, TC and LS.
} 
slope coefficient of a linear trend model when no information about the nature of the noise component is available. In case of rejection of the null, we test for the presence of two structural breaks in the slope $(K=2)$ using the testing approach of Kejriwal and Perron (2010) $\left(\operatorname{Exp} W(2 \mid 1)\right.$ test). The null hypothesis is $\beta_{2}=0$ against $\beta_{2} \neq 0$. Kejriwal and Perron (2010) extend the work of Perron and Yabu (2009b) and propose a sequential test that allows to test the null of $K$ breaks versus an alternative hypothesis of $(K+1)$ breaks and which is consistent whether the noise component is $\mathrm{I}(0)$ or $\mathrm{I}(1)$. The rejection of the null will suggest the existence of two breaks in the slope and one if the test fails to reject.

\subsection{Stationarity tests}

Given evidence of the trend function characteristics (change in slope or not), appropriate unit root tests have to be implemented. Due to the strong change in the behavior of the series, we test the presence of a unit root in subsamples, defined according to the break in slope. However, it is well-known that performance of unit root tests depends whether or not they include a deterministic trend. For that, we use the procedure suggested by Perron and Yabu (2009a) who propose a test $\left(t_{\beta}^{R Q F}\right.$ test) on the slope of the trend function without no prior knowledge to the non-stationary properties of the noise component.

The test assumes that $y_{t}$ is generated by

$$
\begin{aligned}
& y_{t}=\mu_{0}+\beta_{0}+u_{t}, \quad t=1, . ., T \\
& u_{t}=\alpha u_{t-1}+\sum_{i=0}^{\infty} a_{i}^{*} L^{i} \Delta u_{t-i}+e_{t},
\end{aligned}
$$

where $\mu_{0}$ a finite constant, $a_{i}^{*}=-\sum_{j=i+1}^{\infty} a_{j} ; e_{t} \sim$ i.i.d. $\left(0, \sigma^{2}\right)$. Here $-1<\alpha \leq 1$ so that both stationary or integrated errors are allowed.

Following the results on the presence or not of the linear trend $\left(t_{\beta}^{R Q F}\right)$ we apply the unit root tests of Elliott et al. (1996) ( $A D F^{G L S}$ test) with the appropriate deterministic component.

\section{Empirical results and comments}

In the empirical study, we use annual data collected from several statistical surveys, entitled 'Enquête sur la fréquentation touristique à La Réunion', generated over the 
period 1981-2015 by the National Institute of Statistics and Economic Studies 9 Three types of series are considered, namely, (i) total tourist arrivals to La Réunion; (ii) tourist arrivals to La Réunion disaggregated from major source markets, namely, from France, the European Union, and others (e.g. Mauritius, Madagascar, Mayotte, China); and (iii) tourist arrivals to La Réunion disaggregated from visiting motivations (categories), namely, leisure tourism, business tourism, visiting family or friends, and others forms (sport, healthcare ...). The selection of samples and time series span are, of course, dictated by data availability. Therefore, the results should be taken cautiously due to this small sample. Moreover, all data were converted in natural logarithmic form.

\subsection{Breaks detection and unit root tests}

Following the aforementioned methodology, we begin our investigation by testing if the tourism series have been affected by exogenous breaks. In Table 2 , all detected exogenous breaks are given by series, with their type, $t$-statistics, and timing. Our results indicate that the series relative to total arrivals, tourism from continental France, tourism from the European Union, leisure tourism, and visiting family or friends are affected by one break in 2006. This break has a short-lived effect (AO), namely, one year, for total arrivals and visiting family or friends, with a decrease of $32 \%$ and $27 \%$, respectively. The effect is also temporary (TC) for tourism from continental France and leisure tourism, which dies out gradually after few years, with an initial dramatic negative impact of $37 \%$ and 50\%, respectively. For European Union arrivals, the turbulence is observed to have, instead, a permanent impact (LS) that implies a change in the series, but only on the level and not on the slope of the trend. No impact on the growth rate is found, that is, after the shock the growth rate of tourist arrivals converges towards its long-term equilibrium path. The year 2006 corresponds to the health crisis of 'Chickgungunya,' which led to several hundred deaths in few months. By contrast, no exogenous outliers or breaks (large shocks) are detected for the series of other source markets, business tourism, and other tourism motivations.

Surprisingly, at this stage, no statistical effect of the well-known adverse events associated with a large shock (the terrorism context associated with the September 11 terrorist attacks, the international financial crisis in 2008, or the shark crisis damaging the local economy since 2012) is found from our simulations.

\footnotetext{
${ }^{9}$ For the period 1981-1988, the database was reconstructed from information given in DCBFODT (1994).
} 
Table 2: Results of exogenous and endogenous breaks - 1981-2015

\begin{tabular}{|c|c|c|c|c|c|c|}
\hline \multirow[b]{2}{*}{ Series } & \multicolumn{3}{|c|}{ Exogenous break } & \multicolumn{3}{|c|}{ Endogenous break } \\
\hline & type & $t$-stat & date & $\operatorname{ExpW}$ & $\operatorname{Exp} W(2 \mid 1)$ & TB \\
\hline \multicolumn{7}{|l|}{$N b$. of tourists } \\
\hline Total & $\mathrm{AO}$ & -6.54 & 2006 & $30.1^{*}$ & 0.81 & 2000 \\
\hline \multicolumn{7}{|l|}{ Residence } \\
\hline Metropole & $\mathrm{TC}$ & -7.66 & 2006 & $1.29^{* * *}$ & 1.60 & 2000 \\
\hline European Union & $\mathrm{LS}$ & -3.94 & 2005 & $13.6^{*}$ & 0.91 & 1995 \\
\hline Other resid. & - & - & - & $5.57^{*}$ & 1.16 & 1999 \\
\hline \multicolumn{7}{|l|}{ Category } \\
\hline Leisure tourism & $\mathrm{TC}$ & -6.97 & 2006 & $3.75^{*}$ & 0.56 & 1999 \\
\hline Business tourism & - & - & - & -0.13 & - & - \\
\hline Visit family & $\mathrm{AO}$ & -3.99 & 2006 & $8.77^{*}$ & 1.22 & 2004 \\
\hline Other visiting & $\mathrm{TC}$ & -6.06 & 2008 & $1.37^{* * *}$ & 0.75 & 1997 \\
\hline
\end{tabular}

Notes: The test statistics $\operatorname{Exp} W$ and $\operatorname{Exp} W(2 \mid 1)$ denote the Perron-Yabu (2009b) and Kejriwal and Perron (2010) statistics, respectively. The corresponding critical values are 1.67 and 2.56 , respectively. ${ }^{*},{ }^{* *}$ and ${ }^{* * *}$ denotes significance at the $1 \%, 5 \%$ and $10 \%$ level, respectively. Sources: The authors.

Next, we examine if the tourism series has been subject to (endogenous) slope breaks. The tests of Perron and Yabu (2009b) and Kejriwal and Perron (2010) are employed for this purpose on the raw series for other source markets, business tourism, and other tourism motivations and the corrected-outlier series for total arrivals, tourism from continental France, tourism from the European Union, leisure tourism, and visiting family or friends. Table 2 displays the results of the zero versus one slope break $(\operatorname{Exp} W)$, and one versus two slope breaks $(\operatorname{Exp} W(2 \mid 1))$. Kejriwal and Lopez (2013) labelled the case of a break in slope with possible shifts in the level as the 'growth shift' hypothesis.

Our empirical results are notable and potentially informative for economic policy. First, one endogenous break is detected in 2000 for total arrivals and continental France tourists. Similarly, one slope break is present in 1999 for leisure tourism and other source markets, in 2004 for tourists visiting family and friends, and in 1997 for other visiting motivations. More precisely, before the break is an increasing deterministic trend and no trend after the break, except for the series of other source markets where we observe a weak declining trend. The stagnation occurring since the end of the 1990s for the series of other source markets (mainly tourists from Comoros, 
Mayotte, Madagascar, Mauritius, and the Seychelles) and other motivations has the same origins. Starting in the 1990s, important structural changes in the healthcare system within the Southern Indian ocean region were implemented and based on (i) major improvements in medical infrastructure in Mayotte with the implementation of a modern hospital in 1996, and (ii) the growing preference of patients from Mauritius and Seychelles for treatment in South Africa and India due to a significant gap pricecompetitiveness (Dupilet et al., 2011). For the other series, even if no apparent event can be associated with these dates at this point, a possible explanation relies on the structure of the domestic tourism industry and failure of local governance in accordance with the theoretical insights exposed.

Second, the break in the slope for European arrivals identified in 1995 is followed by a strong accelerating trend over the more recent period. This corresponds to a positive change, unfortunately too modest, in the tourist product design more in phase with the expectations of German or Swiss customers. Notably, during the 1990s local authorities in charge of tourism development abandoned the old strategy based on traditional seaside tourism for a more adapted strategy that focused on the combination of the mountains, volcano, sea, and culture. Finally, no evidence of break in the slope was observed for business tourism.

The last important question is if the shocks that are the impetus for the fluctuations of tourist arrivals have permanent or transitory effects on tourist arrivals in La Réunion. Table 3 presents the results of the univariate unit root tests. Four main findings must be underlined: (i) a different stationary process for business tourism; (ii) a change in persistence after the break date in the slope from trend stationarity to difference stationarity for European visitors; (iii) a change in persistence from either difference stationarity or trend stationarity to stationarity without trend due to the break date in the slope for the series of total arrivals, leisure tourism, other visiting motivations, French tourist arrivals and tourists visiting family and friends; and (iv) a change in persistence resulting from the slope break from difference stationarity to trend stationarity for tourist arrivals from other market sources. Overall, our simulations tend to support the transitory effect of external shocks, except for European tourist arrivals and business visitation. however, these two types of tourism represent only marginal inflows. Thus, the actual difficulties of La Réunion's tourism sector are not rooted in the presence of external shocks. 


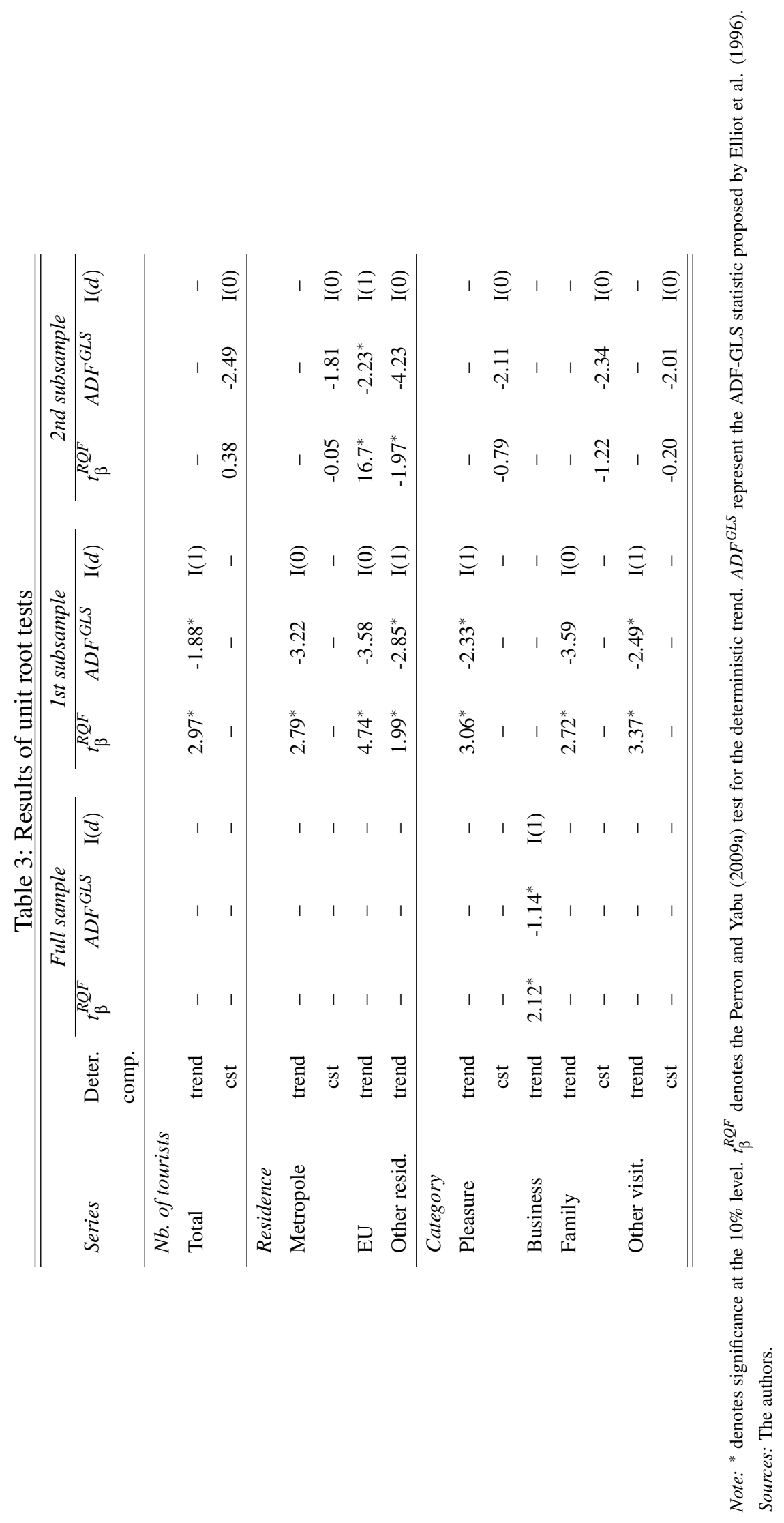




\subsection{Comparing to the literature}

Our results are consistent with the literature, in that a consensus emerges regarding the rejection of the hypothesis of non-stationarity and then supports the finding that external shocks have only a transitory effect on tourist arrivals. By using the Sen (2003) test for one break in linear trending data to investigate whether shocks to visitor arrivals to Fiji from three main source markets (Australia, New Zealand and the United States) have a permanent or transitory effect, Narayan (2005) concluded that tourism arrivals over the period 1970-2002 are finally trend-reverting. By using the panel unit root tests of Maddala and Wu (1999) and Im, Pesaran and Shin (2003) for the period 1980-1999, Bhattacharya and Narayan (2005) indicated that visitor arrivals in India are inconsistent with the random walk hypothesis.

Smyth et al. (2009) applied univariate and panel LM unit root procedures with one and two structural breaks to test for the null hypothesis that tourist arrivals to Bali contain a unit root. They showed that the univariate unit root tests with and without structural breaks did not reject the null of non-stationarity; however, the panel LM ones with one and two structural breaks are able to reject the joint null for the 11 major tourist source markets of Bali, then arguing for jointly trend stationary with transitory shocks. Lean and Smyth (2009) also considered the univariate LM unit root tests with one and two breaks to analyse the effect of shocks for the sustainability of the Malaysian tourism sector over the period 1995-2005 but were unable to reject the unit root null for the 10 main source markets of Malaysia, then validating the hypothesis of trend-stationary with transitory shocks. Lastly, Saleh et al. (2011) conducted univariate and panel LM unit root tests with structural breaks for tourist arrivals to Thailand from its 10 major sources from 1988 to 2007 and found evidence for trend stationarity.

\section{Conclusion}

This paper aimed to study whether the absence of growth in international tourist arrivals to La Réunion since 2000 was due to some large external shocks affecting the growth of this economy (such as the September 11 terrorist attacks, 'Chigungunya' crisis in 2005-2006, international financial crisis in 2008, and shark attacks since 2012). We implemented univariate unit root tests with structural breaks and found no evidence of the permanent impact of external shocks on tourism flows to $\mathrm{La}$ Réunion over the period 1989-2015, except for tourists arriving from the European Union; notably, the European source market represents a small part of total tourism. Moreover, only one major shock, namely, the Chigungunya crisis, was observed to 
have a significant effect on the level of inflows without changing the growth rate. Nevertheless, the results must be considered with caution due to the small sample of the data.

Our findings have operational consequences for economic policy. La Réunion is locked into the phase of exploration of the TALC model, not because of external events, but potentially because of oppressive impediments inside the tourism industry. In short, the trouble is not exogenous but obviously endogenous. Thus, by following the TALC model, the destination should firstly improve the supply side. Building new hotel infrastructure, opening the air traffic with new companies from emerging source markets, and designing a strong and clear tourism identity are examples of policies that must be undertaken urgently.

Otherwise, the findings provide strong support for the recent report from the National Court of auditors in 2014, concerning the tourism performance of the French overseas regions including La Réunion. Resuming the conclusion of this report, 'the decrease in tourist arrivals results especially from structural reasons and by the lack of dynamism of implemented public policies. The successive regional councils do not succeed in coordinating a sector concerning all levels of local administration. A preference is conferred to promoting initiatives but they are largely inefficient, while the supply do not correspond to the expectations of international tourism' (National Court of auditors, 2014). 


\section{References}

[1] Adamou, A., Clerides, S. (2010). Propects and limits of tourism-led growth: The international evidence. Review of Economic Analysis, 3, 287-303.

[2] Agarwal, S. (1994). The resort cycle revisited: Implications for resorts. Progress in Tourism, Recreation and Hospitality Management, 5 194-208.

[3] Agarwal, S. (2002). Restructuring seaside tourism: The resort lifecyle. Annals of Tourism Research, 29(1), 25-55.

[4] Agarwal, S. (2006). Coastal resort restructuring and the TALC. In Butler R.W. (eds), The tourism area life cycle: Conceptual and theoretical issues, Channelview Publications, Clevedon, 201-218.

[5] Dupilet, C., Cash, R., Weill, O., Maguerez, G. (2011). Prises en charge spécialisées des patients des pays de l'Océan Indien dans les hôpitaux de La Réunion : Etats des lieux et propositions. Document de travail de l'AFD, 107, 1-66.

[6] Aguilo, E., Alegre, J., Sard, M. (2005). The persistence of the sun and sand tourism model. Tourism Management, 26(2), 219-231.

[7] Balaguer, J., Cantavella-Jorda, M. (2002). Tourism as a long-run economic growth factor: The Spanish case. Applied Economics, 34, 877-884.

[8] Balke, N., Fomby, T.B. (1994). Large shocks, small shocks, and economic fluctuations: Outliers in macroeconomic time series. Journal of Applied Econometrics, 9, 181-200.

[9] Baum, T.G. (2006). Revisiting the TALC: Is there an off-ramp? In Butler R.W. (eds), The tourism area life cycle: Conceptual and theoretical issues, Channelview Publications, Clevedon, 219-230.

[10] Bertram, G., Poirine, B. (2007). Island political economy. In G. Baldacchino (eds), A world of islands: an island studies reader, Canada and Malta, Institute of Island Studies and Agenda Academic, 332-378.

[11] Bhattacharya, M., Narayan, PP.K. (2005). Testing for the random walk hypothesis in the case of visitor arrivals: evidence from Indian tourism. Applied Economics, 37, 1485-1490. 
[12] Bianchi, R. (1994). Tourism development and tourism dynamics: an alternative approach. Progress in tourism, Recreation and Hospitality Management, 5, 181193.

[13] Blancard, S. Hoarau, J.F. (2016). La détermination d'un optimum touristique à travers la construction d'un Indicateur multidimensionnel de Pénétration Touristique pour les économies insulaires. In J.F. Hoarau (eds), Spécialisation touristique et vulnérabilité: Réalités et enjeux pour le développement soutenable des petits territoires insulaires, L'Harmattan, Collection Tourisme et Sociétés, Partie 3, 229-253.

[14] Box, G.E.P., Tiao, G.C. (1975). Intervention analysis with applications to economic and environmental problems. Journal of the American Statistical Association, 70, 70-79.

[15] Butler, R.W. (1980). The concept of the tourist area life cycle of evolution: implications for management of resources. Canadian Geographer, 24(1), 5-12.

[16] Butler, R.W. (2006). The tourist area life cycle: Conceptual and theoretical issues. Channelview Publications, Clevedon.

[17] Butler, R.W. (2009). Tourism in the future: Cycles, waves and wheels? Futures, 41, 346-352.

[18] Butler, R.W. (2011). Tourism area life cycle: Contemporary tourism reviews. Goodfellow Publishers Ltd, Oxford, 1-33.

[19] Carrion-i-Silvestre, J.L., Kim, D., Perron, P. (2009). GLS-based unit root tests with multiple structural breaks both under the null and the alternative hypotheses. Econometric Theory 25, 1754-1792.

[20] Chen, C., Liu, L. (1993). Joint estimation of model parameters and outlier effects in time series. Journal of the American Statistical Association, 88, 284-297.

[21] Choy, D.J.L. (1992). Life cycle models for Pacific island destinations. Journal of Travel Research, 30, 26-38.

[22] Cole, S. (2007). Beyond the resort life cycle: The micro-dynamics of destination tourism. The Journal of Regional Analysis \& Policy, 37(3), 266-278.

[23] Cole, S. (2009). A logistic tourism model: Resort cycles, globalization, and chaos. Annals of Tourism Research, 36(4), 689-714. 
[24] Darné , O., Diebolt, C. (2004). Unit roots and infrequent large shocks: New international evidence on output. Journal of Monetary Economics, 51, 14491465 .

[25] Delegated central bank for the French overseas departments and territories (DCBFODT) (1994). La Reunion. November, 374p.

[26] Dodds, R., McElroy, J.L. (2008). St Kitts at a crossroads. ARA Journal of Travel Research, 1(2), 1-10.

[27] Elliott, G., Rothenberg, T.J., Stock, J.H. (1996). Efficient tests for an autoregressive unit root. Econometrica, 64, 813-836.

[28] Faulkner, B, Russell, R. (2001). Turbulence, chaos, and complexity in tourism systems: A research direction for the new millennium. In B. Faulkner, G. Moscardo, E. Laws (eds), Tourism and the $21^{\text {st }}$ century: Reflections on experience, London: Continuum Books, 328-349.

[29] Geronimi, V., Zugravu, N., Le Gargasson, Ch., Tsang King Sang, J. (2015). Tourism as a factor of vulnerabilities? The role of insular heritages. Region and Development, 42, 189-214.

[30] Harvey, D. I., Leybourne, S. J., Taylor, A. R. (2010). Robust methods for detecting multiple level breaks in autocorrelated time series. Journal of Econometrics, 157(2), 342-358.

[31] Hoarau, J.F. (2016). Spécialisation touristique et vulnérabilité: Réalités et enjeux pour le développement soutenable des petits territoires insulaires. L'Harmattan, Collection Tourisme et Sociétés, 378p.

[32] Holzner, M. (2011). Tourism and economic development: The beach disease? Tourism Management, 32, 922-933.

[33] Jin, J.C. (2011). The effects of tourism on economic growth in Hong Kong. Cornell Hospitality Quarterly, 52(3), 333-340.

[34] Kejriwal, M., Lopez, C. (2013). Unit roots, level shifts, and trend breaks in per capita output: A robust evaluation. Econometric Reviews, 32, 892-927.

[35] Kejriwal, M., Perron, P. (2010). A sequential procedure to determine the number of breaks in trend with an integrated or stationary noise component. Journal of Time Series Analysis, 31(5), 305-328. 
[36] Komppula, R., Hakulinen, S., Saraniemi, S. (2010). The life cycle of a specific tourist product - Christmas in Lapdand. In Keller P. and Bieger T. (eds), Managing change in tourism, Berlin: Erich Schmidt Verlag.

[37] Lean, H., Smyth, R. (2009). Asian financial crisis, avian flu, and terrorit threats: are shocks to Malaysian tourist arrivals permanent or transitory? Asia Pacific Journal of Tourism Research, 4(3), 301-321.

[38] Logossah, K. Maupertuis, M.A. (2007). Does tourism specialization mean sustainable growth for small developing islands ? Journal of Regional and Urban Economics, 1, 35-55.

[39] Lozato-Giotart, J.P. (2003). Géographie du tourisme : de l'espace consommé à l'espace maitrisé, Pearson Education France, Paris.

[40] Lozato-Giotard, J.P., Balfet, M. (2004). Management du tourisme, Collection tourisme, Pearson Education France, Paris.

[41] McElroy, J.L., de Albuquerque, K. (1998). Tourism penetration index in small Caribbean islands. Annals of Tourism Research, 25(1), 145-168.

[42] McKercher, R. (2006). Are psychographics predictors of destination life cycles? Journal of Travel and Tourism Marketing, 19(1), 49-55.

[43] Moss, S.E., Ryan, C., Wagoner, C.B. (2003). An empirical test of Butler's resort product life cycle: Forecasting casino winnings. Journal of Travel research, 41(4), 393-399.

[44] Narayan, P.K. (2005). Testing the unit root hypothesis when the alternative is a trend break stationary process: an application to tourist arrivals in Fiji. Tourism Economics, 11(3), 351-364.

[45] Narayan, P.K., Prasad, A. (2008). Examining the behavior of visitor arrivals to Australia from twenty different countries: An application of panel unit root tests. Economic Papers, 27(3), 265-271.

[46] National Court of Auditors (2014). National Court of Auditors' Report, 11 february.

[47] Ng, S., Perron, P. (2001). Lag length selection and the construction of unit root tests with good size and power. Econometrica, 69, 1519-1554. 
[48] Nowak, J.J., Sahli, M. (2007). Coastal tourism and dutch disease in a small island economy, Tourism Economics, 13(1), 49-65.

[49] Nowak, J.J., Sahli, M. (2010). Le tourisme, un danger pour les pays en développement? Secteur Prové \& Développement : La revue de PROPARCO, 7, 11-13, septembre.

[50] Perrain, D., Jean-Pierre, Ph. (2016). Quelle(s) stratégie(s) touristique(s) pour les Départements d'outre-mer (DROM) français ? Le cas de l'Île de La Réunion. In J.F. Hoarau (eds), Spécialisation touristique et vulnérabilité: Réalités et enjeux pour le développement soutenable des petits territoires insulaires, L'Harmattan, Collection Tourisme et Sociétés, Partie 4, 275-300.

[51] Perron, P., Qu, Z. (2007). A simple modification to improve the finite sample properties of $\mathrm{Ng}$ and Perron's unit root tests. Economics Letters, 94, 12-19.

[52] Perron, P., Rodriguez, G. (2003). GLS detrending, efficient unit root tests and structural change. Journal of Econometrics, 115, 1-27.

[53] Perron, P., Yabu, T. (2009). Testing for shifts in trend with an integrated or stationary noise component. Journal of Business \& Economic Statistics, 27(3), 369-396.

[54] Prideaux, B. (2000). The resort development spectrum (a new approach to modelling resort development). Tourism Management, 21, 225-240.

[55] Rochoux, J.Y. (2016). La Réunion et son développement touristique: une histoire mouvementée. In J.F. Hoarau (eds), Spécialisation touristique et vulnérabilité: Réalités et enjeux pour le développement soutenable des petits territoires insulaires, L'Harmattan, Collection Tourisme et Sociétés, Partie 3, 205-225.

[56] Russell, R. (2006). Chaos theory and its applications to the tourism area life cycle model. In Butler R.W. (eds), The tourism area life cycle: Conceptual and theoretical issues, Channelview Publications, Clevedon, 164-179.

[57] Russell, R., Faulkner, B. (2004). Entrepreneurship, chaos, and the tourism area life cycle. Annals of Tourism Reasearch, 31(3), 556-579.

[58] Smyth, R., Nielsen, I., Mishra, V. (2009). 'I've been to Bali too' (and I will be going back): are terrorist shocks to Bali's tourist arrivals permanent or transitory?. Applied Economics, 41, 1367-1378. 
[59] United Nations Environment Programme and World Tourism Organization (2006). Making tourism more sustainable: a guide for policvy makers. Madrid, Spain.

[60] Verma, R., Saleh, A.S., Ihala,ayake, R. (2011). Do external shocks have a permanent or a transitory effect on Thailand's tourism industry?. Tourism Analysis, 16(4), 483-491.

[61] Zimmermann, F. (1997). Futures perspectives tourism: Traditionnal versus destinations. In Opperman M. (eds), Pacific Rim Tourism, CAB International: Wallingford, 231-239. 


\section{Appendix: Methodology}

\subsection{Detection of exogenous breaks}

Chen and Liu (1993) and Gómez and Maravall (1997) suggest the following procedure to detect outliers: An ARIMA model is fitted to $y_{t}$ in equation (2) and the residuals are obtained:

$$
\hat{a}_{t}=\pi(B) z_{t}
$$

where $\pi(B)=\alpha(B) \phi(B) / \theta(B)=1-\pi_{1} B-\pi_{2} B^{2}-\ldots$

For the three types of breaks in (1), the equation (6) becomes:

$$
\begin{array}{ll}
\mathrm{AO}: & \hat{a}_{t}=a_{t}+\omega_{A O} \pi(B) I_{t}(\tau) \\
\mathrm{LS}: & \hat{a}_{t}=a_{t}+\omega_{L S}[\pi(B) /(1-B)] I_{t}(\tau) \\
\mathrm{TC}: & \hat{a}_{t}=a_{t}+\omega_{T C}[\pi(B) /(1-\delta B)] I_{t}(\tau)
\end{array}
$$

These expressions can be viewed as a regression model for $\hat{a}_{t}$, i.e.,

$$
\hat{a}_{t}=\omega_{i} x_{i, t}+a_{t} \quad i=\mathrm{AO}, \mathrm{LS}, \mathrm{TC},
$$

with $x_{i, t}=0$ for all $i$ and $t<\tau, x_{i, t}=1$ for all $i$ and $t=\tau$, and for $t>\tau$ and $k \geq 1$, $x_{A O, t+k}=-\pi_{k}(\mathrm{AO}), x_{L S, t+k}=1-\sum_{j=1}^{k} \pi_{j}(\mathrm{LS})$, and $x_{T C, t+k}=\delta^{k}-\sum_{j=1}^{k-1} \delta^{k-j} \pi_{j}-\pi_{k}$ (TC), with $k=1, \ldots, T-\tau$.

The detection of the outliers is based on likelihood ratio [LR] statistics, given by:

$$
\begin{array}{ll}
\text { AO: } & \hat{\tau}_{A O}(\tau)=\left[\hat{\omega}_{A O}(\tau) / \hat{\sigma}_{a}\right] /\left(\sum_{t=\tau}^{n} x_{A O, t}^{2}\right)^{1 / 2} \\
\text { LS: } & \hat{\tau}_{L S}(\tau)=\left[\hat{\omega}_{L S}(\tau) / \hat{\sigma}_{a}\right] /\left(\sum_{t=\tau}^{n} x_{L S, t}^{2}\right)^{1 / 2} \\
\text { TC: } & \hat{\tau}_{T C}(\tau)=\left[\hat{\omega}_{T C}(\tau) / \hat{\sigma}_{a}\right] /\left(\sum_{t=\tau}^{n} x_{T C, t}^{2}\right)^{1 / 2} \\
\text { with } & \hat{\omega}_{i}(\tau)=\sum_{t=\tau}^{n} \hat{a}_{t} x_{i, t} / \sum_{t=\tau}^{n} x_{i, t}^{2} \quad \text { for } i=\mathrm{AO}, \mathrm{LS}, \mathrm{TC}, \\
\text { and } & \hat{\omega}_{I O}(\tau)=\hat{a}_{\tau}
\end{array}
$$

where $\hat{\omega}_{i}(\tau)(i=\mathrm{AO}, \mathrm{LS}, \mathrm{TC})$ denotes the estimation of the break impact at time $t=\tau$, and $\hat{\sigma}_{a}$ is an estimate of the variance of the residual process.

Breaks are identified by running a sequential detection procedure, consisting of outer and inner iterations. In the outer iteration, assuming that there are no breaks, 
an initial $\operatorname{ARIMA}(p, d, q)$ model is estimated and the residuals $\left(\hat{a}_{t}\right)$ are obtained. The results from the outer iteration are then used in the inner iteration to identify breaks. The LR test statistics for the four types of outliers are calculated for each observation. The largest absolute value of these test statistics:

$$
\hat{\tau}_{\max }=\max \left|\hat{\tau}_{i}(\tau)\right| \quad i=\mathrm{AO}, \mathrm{LS}, \mathrm{TC} \text { and } \tau=1, \ldots, T
$$

is compared with a critical value, and if the test statistic is larger, a break is found at time $t=\tau_{1}$ and its type is selected $\left(i^{*}\right)$. When a break is detected, the effect of this break is removed from the data as follows: the observation $z_{t}$ is adjusted at time $t=\tau_{1}$ to obtain the corrected $y_{t}$ via (1) using the estimated magnitude $\hat{\omega}_{i^{*}}$ and the appropriate structure of break $f(t)_{i^{*}}$ as in (3), i.e.

$$
y_{t}=z_{t}-f(t)_{i^{*}}
$$

We also compare the second largest absolute value of the LR statistics for the three types of breaks to the critical value, i.e. $\hat{\tau}_{\max }=\max \left|\hat{\tau}_{i}(\tau)\right|$ with $\tau \neq \tau_{1}$, and so on. This process is repeated until no more breaks can be found. Next, we return to the outer iteration in which another $\operatorname{ARIMA}(p, d, q)$ model is re-estimated from the breakcorrected data, and start the inner iteration again. This procedure is repeated until no break is found. Finally, a multiple regression is performed on the various detected breaks to identify (possible) spurious breaks.

\subsection{Detection of endogenous breaks}

Perron and Yabu (2009b) extend the procedure of Perron and Yabu (2009a) to address the issue of testing for structural break in the trend function. The test starts by assuming a data generating process (DGP) for a scalar random variable $y_{t}$ to have the following specification:

$$
\begin{aligned}
& y_{t}=x_{t}^{\prime} \Psi+u_{t}, \quad t=1, . ., T \\
& u_{t}=\alpha u_{t-1}+\sum_{i=0}^{\infty} a_{i}^{*} L^{i} \Delta u_{t-i}+e_{t},
\end{aligned}
$$

where $x_{t}=\left(1, t, D T_{t}\right)^{\prime}, \Psi=\left(\mu_{0}, \beta_{0}, \beta 1\right)^{\prime}, D T_{t}=1\left(t>T_{1}\right)\left(t-T_{1}\right), T_{1}=\left[\lambda_{1} T\right]=$ the break date. The null hypothesis of the test for a shift in slope (allowing for a shift in intercept) is $H_{0}: \beta_{1}=0$ versus $H_{1}: \beta_{1} \neq 0$.

The Wald test statistic $W^{R Q F}$ is constructed for a given break fraction $\lambda_{1}$ and depending on the value of $\hat{\alpha}_{M S}$

$$
W^{R Q F}\left(\lambda_{1}\right)=\frac{\left(\hat{\beta}_{1}^{F G}\left(\lambda_{1}\right)\right)^{2}}{\sqrt{\hat{h}_{\mathrm{v}}\left[\left(X^{\prime} X\right)^{-1}\right]_{44}}}
$$


where $X=\left[x_{1},\left(1-\hat{\alpha}_{M S} L\right) x_{t}(t=2, \ldots, T)\right]$, and $\hat{\beta}_{1}^{F G}$ is quasi FGLS estimate of $\beta_{1}{ }^{10}$ Following Andrews (1993) and Andrews and Ploberger (1994), Perron and Yabu (2009b) consider the Exp functional of the Wald test for different break dates as they found the limit distributions to be nearly identical in the $\mathrm{I}(0)$ and $\mathrm{I}(1)$ cases. The test statistic needs to be evaluated for each break date candidate and then, the Exp functional as defined as follows is evaluated:

$$
\operatorname{Exp} W=\log \left[T^{-1} \sum_{\lambda_{1} \in \Lambda_{1}} \exp \left(\frac{1}{2} W^{R Q F}\left(\lambda_{1}\right)\right)\right]
$$

Kejriwal and Perron (2010) extend the approach of Perron and Yabu (2009b) and propose a sequential test that allows to test the null hypothesis of $l$ breaks against the alternative hypothesis of $(l+1)$ changes. The procedure is consistent to wether the data are stationary or not. As in Perron and Yabu (2009b), Kejriwal and Perron (2010) use the Exp functional over all permissible break dates.

$$
\operatorname{Exp}_{(i)}^{R Q F}=\log \left[\left(\hat{T}_{i}-\hat{T}_{i-1}\right)^{-1} \sum_{\tau \in \Lambda_{i, \varepsilon}} \exp \left(\frac{W_{R Q F}\left(\hat{\lambda}_{i-1}, \tau, \hat{\lambda}_{i}\right)}{2}\right)\right]
$$

where $\tau \in \Lambda_{i, \varepsilon}=\left\{\tau: \hat{\lambda}_{i-1}+\left(\hat{\lambda}_{i}-\hat{\lambda}_{i-1}\right) \varepsilon \leq \tau \leq \hat{\lambda}_{i}-\left(\hat{\lambda}_{i}-\hat{\lambda}_{i-1}\right) \varepsilon\right\}$ with $\hat{\lambda}_{i}=\hat{T}_{i} / T$ and $\operatorname{Exp}_{R Q F}^{(i)}$ is the one break test in segment $i$. For $i=1, \ldots, l+1$, the sequential test is the application of a single change in slope (allowing for shift in level) test in the $(l+1)$ segments and examine if the maximum is significant. The test is given by:

$$
F_{T}(l+1 \mid l)=\max _{1 \leq i \leq l+1}\left\{\operatorname{Exp}_{(i)}^{R Q F}\right\}
$$

The first step is to investigate if there at least one break $\left(F_{T}(1 \mid 0)\right)$. In case of rejection, the test $F_{T}(2 \mid 1)$ is applied. If the statistic is sufficiently large we conclude in favor of two breaks in the DGP. Notice that the test is repeated by increasing $l$ sequentially until the test fails to reject the null hypothesis of no structural change, the number of breaks corresponding then to the number of rejections. However, in our study we limited $l$ to unity.

\footnotetext{
${ }^{10}$ The approach consists to consider the quasi FGLS estimate of the parameters of the equation 15 using $\hat{\alpha}_{M S}$ :

$$
\left(1-\hat{\alpha}_{M S} L\right) y_{t}=\left(1-\hat{\alpha}_{M S} L\right) x_{t}^{\prime} \Psi+\left(1-\hat{\alpha}_{M S} L\right) u_{t}
$$

$t=2, \ldots, T$, and $y_{1}=x_{1}^{\prime} \Psi+u_{1}$. Denote the resulting estimates by $\hat{\Psi}^{F G}=\left(\hat{\mu}_{0}^{F G}, \hat{\mu}_{1}^{F G}, \hat{\beta}_{0}^{F G}, \hat{\beta}_{1}^{F G}\right)^{\prime}$.
} 


\subsection{Trend test}

Perron and Yabu (2009a) recommend the following steps for testing the slope of the trend function without no prior knowledge to the non-stationary properties of the noise component:

1. Estimate the residuals $\hat{u_{t}}$ from detrended $y_{t}$ by OLS.

2. Estimate $\alpha$ from the following regression:

$$
\hat{u}_{t}=\alpha \hat{u}_{t-1}+\sum_{i=1}^{k} \zeta_{i} \Delta \hat{u}_{t-i}+e_{t k}
$$

The order $k$ is selected using the Modified AIC of $\mathrm{Ng}$ and perron (2001) (MAIC), with $k \in\left[0 ; 12(T / 100)^{1 / 4}\right]$

3. Since the OLS estimate of $\alpha$ is biased downward, especially when $\alpha$ is near one, Perron and Yabu (2009a) recommend the bias correction proposed by Roy and Fuller (2001) $\hat{\alpha}_{M S}$.

4. Apply the quasi feasible generalized least square (FGLS) procedure using $\hat{\alpha}_{M S}$ to obtain the estimate of the trend parameter $\beta_{0}$

$$
\left(1-\hat{\alpha}_{M S} L\right) y_{t}=\left(1-\hat{\alpha}_{M S}\right) \mu_{0}+\beta_{0}\left[t-\hat{\alpha}_{M S}(t-1)\right]+\left(1-\hat{\alpha}_{M S} L\right) u_{t}
$$

$t=2, \ldots, T$, and $y_{1}=\mu_{0}+\beta_{0}+u_{1}$. Denote the resulting estimates of $\beta_{0}$ by $\hat{\beta}_{0}^{F G}$.

5. Construct the $t$-statistic $t_{\beta}^{R Q F}$ (where RQF stands for robust quasi FGLS)

$$
t_{\beta}^{R Q F}=\frac{\left(\hat{\beta}_{0}^{F G}-\beta_{0}\right)}{\sqrt{\hat{h}_{v}\left[\left(X^{\prime} X\right)^{-1}\right]_{22}}}
$$

where $X=\left[x_{1}, \ldots, x_{T}\right]^{\prime}, x_{t}^{\prime}=\left[\left(1-\hat{\alpha}_{M S}\right), t-\hat{\alpha}_{M S}(t-1)\right]$ for $t=2, \ldots, T$, and $x_{1}^{\prime}=(1,1) . h_{v}$ is a consistent estimate of $(2 \pi$ times) the spectral density function at frequency zero of $v_{t}=(1-\alpha L) u_{t}$. They use an autoregressive spectral density estimate.

\subsection{Stationary test}

The unit root test proposed by Elliott et al. (1996) is based on the following regression:

$$
\Delta \tilde{y}_{t}=\beta_{0} \tilde{y}_{t-1}+\sum_{j=1}^{k} \beta_{j} \Delta \tilde{y}_{t-j}+\varepsilon_{t}
$$


in which $\tilde{y}_{t}$ representing the locally detrended data process under the local alternative $\alpha$, is given by:

$$
\tilde{y}_{t}=y_{t}-\hat{\psi}^{\prime} z_{t}
$$

where $z_{t}=(1, t)^{\prime}$ in the case with drift, and $\hat{\psi}$ being the generalized least squares (GLS) regression coefficient of $\bar{X}_{t}$ on $\bar{z}_{t}$ defined by:

$$
\begin{aligned}
\left(\bar{y}_{1}, \bar{y}_{2}, \ldots, \bar{X}_{T}\right) & =\left(y_{1},(1-\alpha B) y_{2}, \ldots,(1-\alpha B) y_{T}\right) \\
\left(\bar{z}_{1}, \bar{z}_{2}, \ldots, \bar{z}_{T}\right) & =\left(z_{1},(1-\alpha B) z_{2}, \ldots,(1-\alpha B) z_{T}\right)
\end{aligned}
$$

The test statistic ADF-GLS is the usual $t$-statistic for the null hypothesis $\beta_{0}=0$ against the alternative of $\beta_{0}<0$. Elliott et al. (1996) recommend that the parameter $c$, defining the local alternative through $\alpha=1-(c / T)$, be set equal to 13.5 if the series seems to contain a trend (drift), and 7 for an intercept. The lag order $k$ is selected using the modified information criteria suggested by Ng and Perron (2001) with the modification proposed by Perron and Qu (2007). 